\title{
Bevolkingsonderzoek naar darmkanker
}

Darmkanker geeft pas laat klachten en de symptomen die op darmkanker kunnen duiden zijn vrij algemeen en kunnen ook heel goed andere oorzaken hebben. Klachten kunnen zijn:

- Bloed en/of slijm bij de faeces of uit de anus

- Veranderde of onregelmatige stoelgang: obstipatie of juist diarree

- Terugkerende buikpijn, vaak gepaard met krampen

Onverklaarbaar gewichtsverlies

Tabel 1. Klachten bij darmkanker. immunochemische faecestesten de mortaliteitswinst hoger, voor deze testen is, meer dan voor de alternatieven, de balans tussen efficiëntie, eenvoud en kosten gunstig. De Gezondheidsraad heeft onlangs geadviseerd bevolkingsonderzoek naar darmkanker met een immunochemische faecestest te beginnen.

Rossum LGM van, Laheij RJF, Jansen JBMJ. Bevolkingsonderzoek naar darmkanker. Ned Tijdschr Tandheelkd 2010; 117: 263-267

\section{Inleiding}

Darmkanker is een groot gezondheidsprobleem met per jaar in Nederland meer dan 11.000 nieuwe gevallen. Dat aantal neemt, vooral door de vergrijzing, elk jaar toe (www.ikcnet. nl). Eén op de 20 mensen, ongeveer evenveel mannen als vrouwen, krijgt gedurende zijn leven darmkanker. Darmkanker geeft meestal pas in een laat stadium klachten, als de prognose slecht is (tab. 1). De 5-jaarsoverleving is gemiddeld 59\%: bijna de helft van de patiënten sterft aan de gevolgen van de kanker. Nieuwe onderzoekstechnieken en nieuwe behandelingen hebben de prognose iets verbeterd, maar het aantal nieuwe gevallen stijgt snel. Jaarlijks sterven daardoor nog steeds meer patiënten aan darmkanker dan in het jaar ervoor. Daar komt bij dat patiënten meestal een sterk verminderde levenskwaliteit hebben. Als het sterftecijfer daalt, betekent dat ook dat meer mensen langer met de ziekte moeten leven.

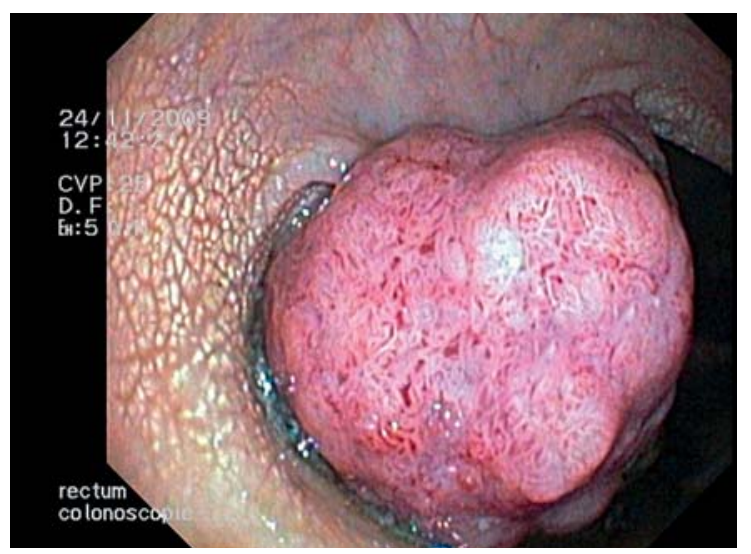

Afb. 1. Darmkanker

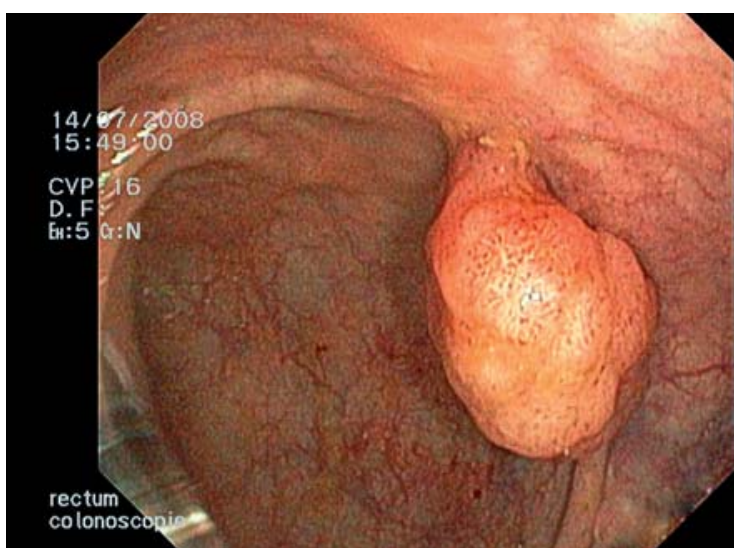

\author{
Erfelijkheid \\ - Hogere leeftijd (vooral ouder dan 50 jaar) \\ Familiair voorkomen \\ - Weinig bewegen, vooral in combinatie met overgewicht \\ - Roken \\ - Veel dierlijke producten, vooral 'rood' vlees, in het dieet
}

Tabel 2. Risicofactoren voor darmkanker.

Darmkanker (afb. 1) kent een relatief lang voorstadium in de vorm van adenomateuze poliepen of adenomen ( $\mathrm{afb} .2$ ).

Adenomen zijn relatief eenvoudig te herkennen en te verwijderen tijdens een coloscopie. Beneden de leeftijd van 50 jaar komen adenomen nauwelijks voor, behalve bij mensen die erfelijk zijn belast. Maar in de leeftijdsgroep van 50 tot 75 jaar heeft gemiddeld 20 tot $40 \%$ van de mensen wel 1 of meer adenomen. Deze ontwikkelen zich gelukkig maar zelden tot darmkanker. Op dit moment is onduidelijk welke adenomen wel en welke niet ontwikkelen tot darmkanker. Daarom is niet te voorspellen wie darmkanker zal krijgen, hoewel een paar risicofactoren te noemen zijn die de kans op darmkanker vergroten (tab. 2).

Afb. 2. Adenoom. 
Adenomen worden op basis van grootte en enkele histologische kenmerken onderverdeeld in gevorderde en niet-gevorderde adenomen. Vooral verwijdering van grote adenomen lijkt de kans op darmkanker te verkleinen (Atkin, 2003). Naar schatting duurt het wel 10 tot 15 jaar voordat een klein adenoom zich ontwikkelt tot darmkanker. Daarna kan het 7 jaar duren voordat sprake is van een vergevorderd stadium met klinische verschijnselen. Daarom zou bevolkingsonderzoek nuttig kunnen zijn. Maar er zijn nog veel andere criteria waaraan moet worden voldaan voor bevolkingsonderzoek kan worden overwogen (tab. 3). In ieder geval moet het mogelijk zijn darmafwijkingen in een vroeger stadium te ontdekken, liefst voordat sprake is van darmkanker (Gezondheidsraad, 2009).

\section{Testen}

Voor screening op darmkanker zijn meerdere testen voorhanden en in ontwikkeling waarmee darmkanker in een vroeg stadium kan worden ontdekt. Het voert hier te ver om alle alternatieven in detail te bespreken en daarom blijft dit artikel beperkt tot een globale beschouwing van de mogelijkheden en beperkingen van endoscopie (coloscopie en sigmoïdoscopie), CT-colografie, faecaaloccultbloedtesten en moleculaire diagnostiek.

\section{Endoscopie}

Een endoscopie is een kijkonderzoek. Via de anus wordt een flexibele slang met een lampje en een camera (endoscoop) geleidelijk door de darm geschoven. Tijdens het terugtrekken van de endoscoop wordt het slijmvlies van de dikke darm goed bekeken. Bij een endoscopie van de dikke darm kunnen de coloscopie en de sigmoïdoscopie worden onderscheiden.

\section{Coloscopie}

Een coloscopie is een kijkonderzoek van de gehele dikke darm en is altijd noodzakelijk om afwijkingen in de dikke darm op te sporen of uit te sluiten - welke screeningsmethode verder ook wordt gebruikt (afb. 3). De meeste (adenomateuze) poliepen kunnen tijdens een coloscopie worden verwijderd. Dat kan ook gelden voor darmtumoren, als ze nog in het vroegste stadium zijn (Van Rossum, 2009). Om het slijmvlies goed te kunnen beoordelen, moet de darm zodanig worden gelaxeerd dat alleen nog vrijwel heldere vloeistof wordt uitgescheiden. Hiervoor moet de patiënt enkele liters laxeermiddel drinken. Dat wordt - begrijpelijk - vaak als zeer onaangenaam ervaren. Het onderzoek zelf is zo onaangenaam dat anesthesie met een roesmiddel standaard is.

Hoewel coloscopie als de gouden standaard voor diagnostiek van darmkanker wordt beschouwd, is het als primaire screeningsmethode mindergeschikt. Devoorbereiding en het onderzoek zijn belastend en een coloscopie brengt risico's met zich mee. Globaal vindt tijdens een screeningscoloscopie bij 1 op de 1.000 mensen een ernstige complicatie plaats die bij 1 op de 10.000 tot 100.000 fataal afloopt (Regula et al, 2006; Niv et al, 2008). Bij een primaire coloscopiescreening wordt in de leeftijdsgroep van 50-75 jaar bij minder dan 1 op de 125 mensen darmkanker gevonden en

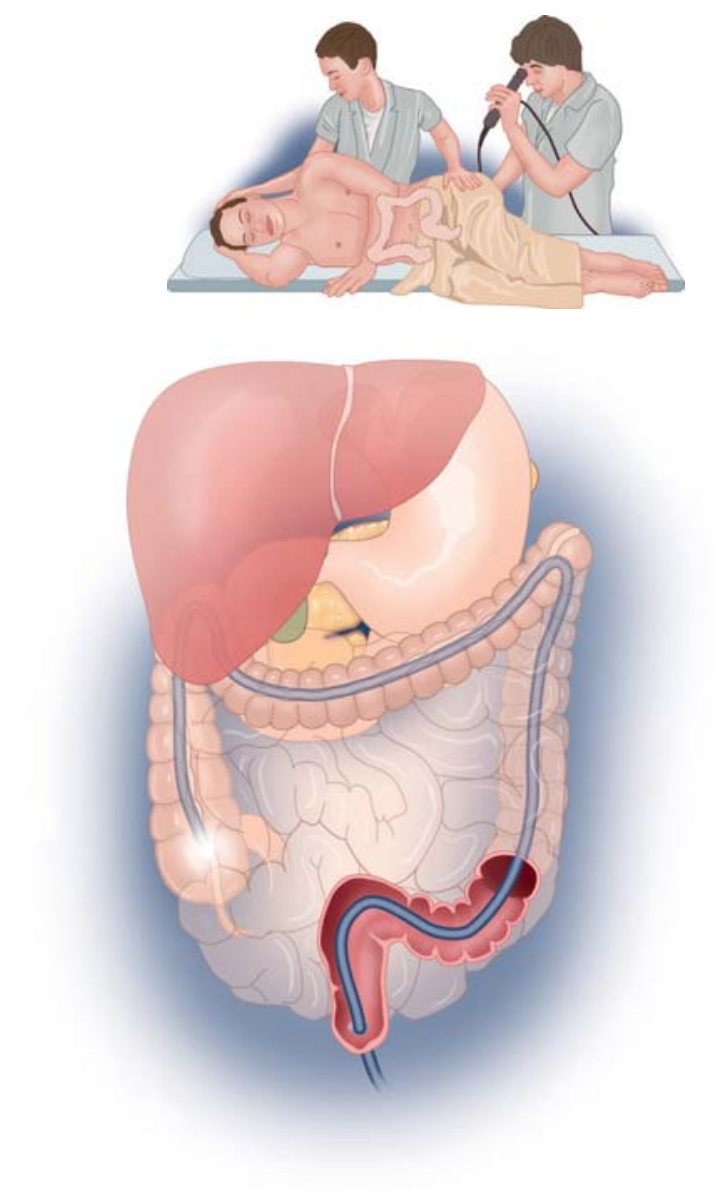

Afb. 3. Coloscopie

bij ongeveer 1 op de 14 mensen 1 of meer gevorderde adenomen (Regula et al, 2006; Segnan et al, 2007; Huppe et al, 2008). 13 van de 14 mensen ondergaan dus onnodig dit risicovolle onderzoek. Daar komt nog bij dat het onderzoek duur en tijdrovend is en dat de opkomst laag is.

\section{Sigmoïdoscopie}

Alle nadelen van coloscopie gelden in mindere mate ook voor sigmoïdoscopie. Bij een sigmoïdoscopie wordt alleen het laatste deel van de darm bekeken: het sigmoïd en het rectum (afb. 4). De voorbereiding hiervoor bestaat meestal alleen uit een klysma en ook het onderzoek zelf is minder belastend. Tijdens een sigmoïdoscopie zijn wat beperktere behandelingen mogelijk dan bij een coloscopie vanwege een gering explosiegevaar door de aanwezigheid van methaangas in de darm. Complicaties bij sigmoïdoscopie komen veel

Screening is gericht op een belangrijk gezondheidsprobleem.

Screening leidt tot gezondheidswinst of andere voordelen voor de te onderzoeken personen.

De screeningsmethode is betrouwbaar en valide.

Deelname aan screening en vervolgonderzoek is gebaseerd op een geïnformeerde en vrijwillige keuze.

De middelen worden doelmatig gebruikt.

Tabel 3. Criteria voor verantwoord bevolkingsonderzoek. 

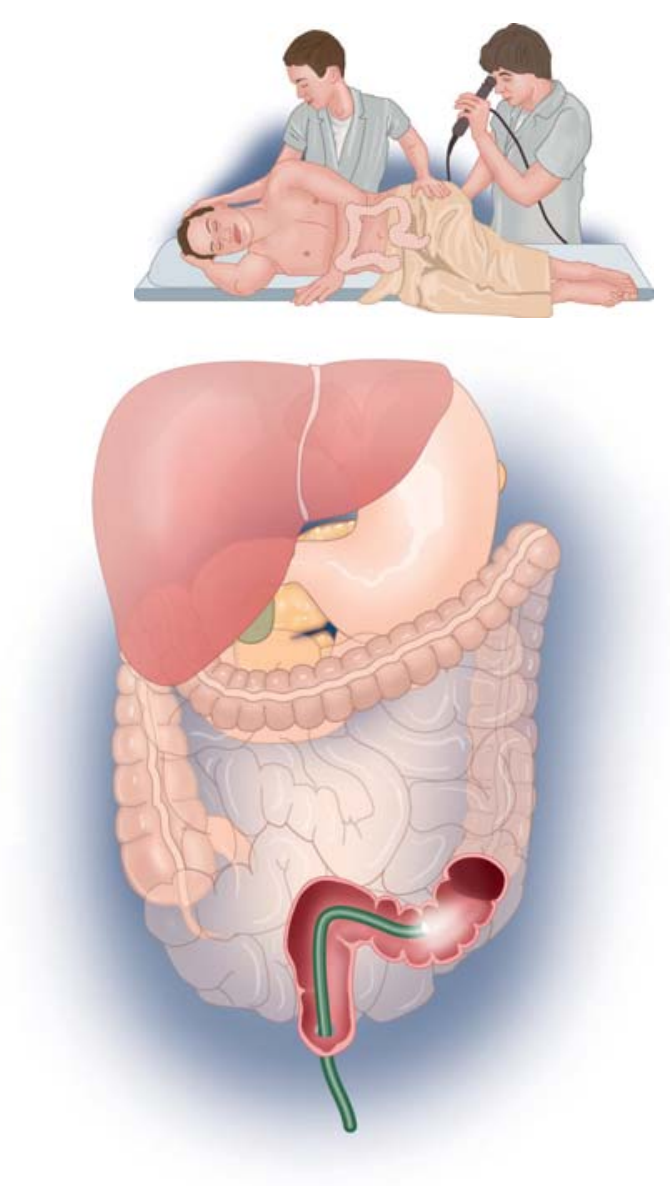

Afb. 4. Sigmoïdoscopie.

minder frequent voor dan bij coloscopie, waarschijnlijk in minder dan 1 op de 30.000 gevallen.

De opkomst bij een recente sigmoïdoscopiescreening was slechts 30\% (Hol, 2010). Bij 10\% bleek de darmvoorbereiding ontoereikend en moest het onderzoek opnieuw worden gedaan. Omdat bij een sigmoïdoscopie maar een beperkt deel van de dikke darm wordt bekeken, wordt relatief veel darmkanker gemist. Darmkanker komt weliswaar het meest voor in het sigmoïd en het rectum, maar de sensitiviteit van sigmoïdoscopiescreening voor darmkanker is maximaal $60 \%$. Dat percentage wordt bovendien alleen gehaald indien bij vondst van adenomen binnen het bereik van de sigmoïdoscopie alsnog een volledige coloscopie wordt uitgevoerd. De patiënt moet dan binnen korte tijd 2 endoscopieën ondergaan (Mulder et al, 2009).

\section{CT-colografie}

Tijdens een CT-colografie (een 'virtuele coloscopie') wordt, in rug- en buikligging, met een aantal röntgenopnamen de darm zichtbaar gemaakt. Daarbij is geen anesthesie nodig. De voorbereiding hiervoor is minder uitgebreid dan voor een coloscopie: 1 dag een vezelarm dieet en inname van een contrastvloeistof. Deze vloeistof werkt laxerend, maar is vooral bedoeld om de faeces en het vocht contrast te geven ten opzichte van het darmslijmvlies. Tijdens het onderzoek wordt door een canule die via de anus wordt ingebracht

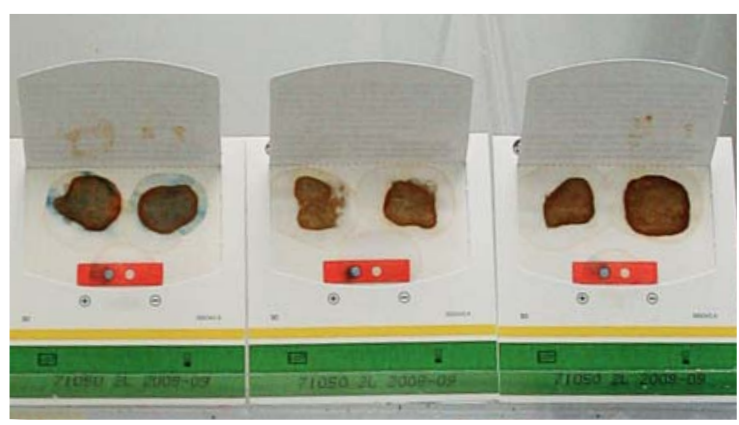

Afb. 5. Guajak-faecaaloccultbloedtest (Hemoccult $\left.{ }^{\circledR}\right)$. Alleen de vakjes in het linker kaartje van de 3 testkaarten zijn positief, zoals te zien is aan de blauwverkleuring.

lucht of kooldioxide in de darm gepompt, waardoor eventuele afwijkingen zichtbaar kunnen worden gemaakt.

Als screeningsmethode heeft de CT-colografie een sensitiviteit van $90 \%$ voor adenomen groter dan $10 \mathrm{~mm}$ en voor darmkanker. De deelnamebereidheid is onbekend, maar, voor zover nu bekend is, nauwelijks hoger dan voor endoscopiescreening (Edwards et al, 2004). CT-colografie is evenals endoscopiescreening kostbaar en tijdrovend en er is sprake van capaciteitsproblemen. Een belangrijk bijkomend probleem is de stralingsbelasting. Voor 1 CT-colografie is niet extreem veel straling nodig, maar ook alle andere röntgendiagnostiek en een eventuele herhaling van de CT-colografie dragen bij aan de totale stralingsbelasting. Het is moeilijk te voorspellen of dit tot stralingsgerelateerde kanker kan leiden. Bovendien is er discussie over de betekenis van afwijkingen die buiten de darm worden aangetroffen. Het is te eenvoudig om deze bijvangst alleen als positief te duiden. Uit onderzoek blijkt dat maar zelden aandoeningen worden gevonden die moeten of kunnen worden behandeld. De kosteneffectiviteit van de bijvangst is laag (Edwards et al, 2001).

Tijdens CT-colografie kan bovendien een darmperforatie optreden, maar na $17.500 \mathrm{CT}$-colografieën in screening is nog geen perforatie gemeld (Gezondheidsraad, 2009). Bij een positief resultaat moet alsnog een coloscopie worden gedaan en moeten daarom ook bij deze methode veel patiënten in korte tijd 2 belastende onderzoeken ondergaan.

\section{Faecaaloccultbloedtest}

Normaal darmslijmvlies bloedt niet, maar slijmvlies dat door darmkanker is aangedaan vaak wel. In mindere mate geldt dit ook voor (gevorderde) adenomen. Dit gegeven kan worden gebruikt om darmkanker op te sporen. De aanwezigheid van bloed kan een indicatie zijn voor darmkanker of gevorderde adenomen. Het bloedverlies is echter meestal pas met het blote oog zichtbaar als de darmkanker in een vergevorderd stadium is. Daarom zijn faecestesten ontwikkeld waarmee aanwezig, met het blote oog onzichtbaar, bloedverlies kan worden vastgesteld: faecaaloccultbloedtesten (FOBT).

$\mathrm{Al}$ sinds de jaren ' 70 van de vorige eeuw bestaat voor bevolkingsonderzoek de methode met de klassieke guajakFOBT (gFOBT). Guajak is een extract van boomhars dat blauw kleurt onder invloed van waterstofperoxide (afb. 5). Dit proces wordt versneld door de peroxidase-activiteit van 


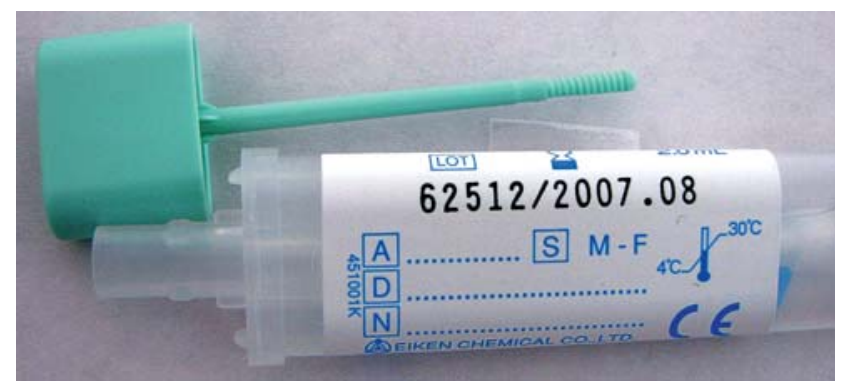

Afb. 6. Immunochemische faecaaloccultbloedtest: het testbuisje.

de heemgroep van hemoglobine in bloed. Een nadeel van deze test is dat ook dierlijk bloed en sommige planten peroxidase-activiteit vertonen. Daardoor kunnen zich foutpositieve uitslagen voordoen. Anderzijds kan bijvoorbeeld een (zeer) hoge dosis vitamine $\mathrm{C}$ de peroxidase-activiteit teniet doen en zo een fout-negatief resultaat geven. Voor de gFOBT is een afname van darmkankersterfte aangetoond, hoewel beperkt: 11 tot $18 \%$ (Heresbach et al, 2006). Een gFOBT heeft slechts een sensitiviteit van ongeveer $20 \%$ voor darmkanker. Voor adenomen is de test niet of verwaarloosbaar sensitief. De deelnamebereidheid is zelden hoger dan 50\%. Door herhaalde testen kan uiteindelijk een cumulatieve sensitiviteit van 60 tot $70 \%$ worden bereikt, maar daarvoor zijn zeker 5 tot 6 testronden nodig.

Vanwege de geringe sensitiviteit en andere nadelen van de gFOBT zijn immunochemische FOBT's ontwikkeld (iFOBT's). Deze testen zijn specifiek voor humaan bloed omdat ze reageren op antistoffen van het globinegedeelte van hemoglobine. In theorie zijn ze ook sensitiever en specifieker dan de gFOBT (afb. 6). Een extra voordeel van (een deel van) deze testen is dat ze kwantitatief zijn en dat ze automatisch kunnen worden verwerkt (afb. 7). Een enkele iFOBT op 1 dag met faeces heeft al 65\% sensitiviteit voor darmkanker en $27 \%$ voor gevorderde adenomen. De sensitiviteit stijgt met elke extra ronde (Morikawa et al, 2005).

In een gerandomiseerd onderzoek is aangetoond dat de deelnamebereidheid bij iFOBT veel groter is dan bij gFOBT. Ook werden veel meer ziektegevallen gevonden (Van Rossum et al, 2008; Hol et al, 2009). In totaal scoort, door de hogere sensitiviteit gecombineerd met de grotere deelname, de iFOBT bijna 3 keer beter dan de gFOBT. Bovendien wordt met iFOBT darmkanker gemiddeld in vroegere stadia ontdekt. Gemiddeld is de 5-jaarsoverleving meer dan 80\% (Van Rossum, 2009). Bij 20 tot 30\% van de darmkankerpatiënten kan de behandeling beperkt blijven tot coloscopie met

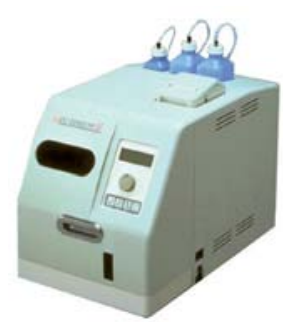

Afb. 7. Immunochemische faecaaloccultbloedtest: de testapparatuur. verwijdering van (pre)maligne weefsels en is chirurgische behandeling niet nodig.

Screening is onlosmakelijk verbonden met fout-positieve uitslagen en onnodige behandelingen, zoals tegenstanders terecht opmerken. Toch zijn patiënten ook wat dat betreft beter af met de iFOBT. Daarmee worden kleine adenomen, de minder gevaarlijke, in mindere mate ontdekt dan tijdens primaire screening met beeldvormende technieken.

\section{Moleculaire diagnostiek}

Er is momenteel veel belangstelling voor moleculaire diagnostiek van darmkanker. Dat betreft over het algemeen testen die gebruikmaken van DNA en soms van RNA. De testen moeten zo specifiek mogelijk op darmkanker reageren en het liefst ook op adenomen. Het blijkt echter moeilijk dergelijke testen te ontwikkelen en daarom wordt vaak gewerkt met zogenoemde 'panels', die feitelijk bestaan uit een aantal testen op een aantal eigenschappen van darmkanker (en adenomen). Hoe meer eigenschappen worden gecombineerd in een panel van testen, hoe groter in theorie de sensitiviteit, maar de kosten stijgen en bovendien daalt de specificiteit. En zelfs met een groot aantal testen in een panel valt de sensitiviteit tegen. Betere en goedkopere moleculaire testen zijn in ontwikkeling, maar het kan nog wel 10 tot 15 jaar duren voordat deze voor bevolkingsonderzoek kunnen worden overwogen.

\section{Slotbeschouwing}

Al in 2001 adviseerde de Gezondheidsraad onderzoek te beginnen naar de mogelijkheid van bevolkingsonderzoek naar darmkanker in Nederland (Gezondheidsraad, 2001). In 2003 adviseerde de Europese Commissie haar lidstaten te beginnen met darmkankerscreening (Commission of the European Communities, 2003). De Gezondheidsraad vindt dat darmkanker zich goed leent voor bevolkingsonderzoek en adviseerde onlangs de minister van Volksgezondheid, Welzijn en Sport positief over landelijke darmkankerscreening met een immunochemische faecaaloccultbloedtest (iFOBT) (Gezondheidsraad, 2009). Onderzoek uit het buitenland toont aan dat er mortaliteitswinst valt te behalen en onderzoek uit Nederland toont aan dat er geen specifieke belemmeringen zijn voor ons land (Heresbach et al, 2006; Van Rossum et al, 2008). Nederlands onderzoek toont ook aan dat bevolkingsonderzoek naar darmkanker economisch zo gunstig is dat het gezien de huidige medische ontwikkelingen per gewonnen levensjaar zelfs kostenbesparend zal zijn (Lansdorp-Vogelaar, 2009). De conclusie dat begonnen kan worden met darmkankerscreening met iFOBT is dan ook goed onderbouwd, hoewel nog veel kan worden onderzocht. Daarom adviseert de Gezondheidsraad structureel budget voor doorlopend onderzoek op te nemen in de begroting voor screening. Bij landelijke screening moet goede registratie, voortdurend onderzoek en kwaliteitsbewaking plaatsvinden en moet de mogelijkheid bestaan het programma eenvoudig aan te passen aan nieuwe inzichten.

De Gezondheidsraad adviseert wel een iets beperktere leeftijdsgroep voor bevolkingsonderzoek uit te nodigen en 
een wat hoger afkappunt te hanteren dan vooralsnog in het Nederlands onderzoek is toegepast: 55-75 jaar in plaats van 50-75 jaar en 75 nanogram humaan hemoglobine per milliliter faeces in plaats van 50. Dat scheelt veel coloscopieën, zonder dat onevenredig veel mensen met darmkanker zullen worden gemist, zeker omdat de screening 2-jaarlijks wordt herhaald. Omdat zelfs met die beperking de capaciteit voor coloscopieën in Nederland niet direct toereikend zal zijn, adviseert de Gezondheidsraad een geleidelijke invoering. Na ongeveer 6 jaar zou een landelijk dekkend screeningsprogramma voor de gehele leeftijdsgroep van 55 tot 75 jaar mogelijk moeten zijn, zonder een bepaalde leeftijdsgroep tekort te doen.

Uit modelberekeningen concludeert de Gezondheidsraad tot slot dat over het komende decennium per jaar gemiddeld 1.400 mensen minder hoeven te overlijden aan darmkanker. Alleen de toekomst zal ons leren of de verwachtingen uit de modelberekeningen zullen worden waargemaakt.

\section{Praktijkconclusie}

In de toekomst kan door bevolkingsonderzoek naar darmkanker waarschijnlijk veel mortaliteitswinst worden geboekt. Het bevolkingsonderzoek zal bestaan uit immunochemische faecestests, omdat deze de beste nut-risicoverhouding hebben. Alleen patiënten met een positieve uitslag op deze test hoeven dan een belastende coloscopie te ondergaan. Structureel onderzoeksbudget en een deels specifieke registratie zullen helpen om het bevolkingsonderzoek zo nodig snel en efficiënt bij te stellen.

\section{Literatuur}

* Atkin W. Options for screening for colorectal cancer. Scand J Gastroenterol Suppl 2003: 13-16.

* Commission of the European Communities. Proposal for a Council Recommendation on cancer screening (presented by the Commission), Brussels: Commission of the European Communities 2003.

* Edwards JT, Mendelson RM, Fritschi L, et al. Colorectal neoplasia screening with CT colonography in average-risk asymptomatic subjects: community-based study. Radiology 2004; 230: 459-464.

* Edwards JT, Wood CJ, Mendelson RM, Forbes GM. Extracolonic findings at virtual colonoscopy: implications for screening programs. Am J Gastroenterol 2001; 96: 3009-3012.

* Gezondheidsraad. Bevolkingsonderzoek naar darmkanker. Signalement. Den Haag: Gezondheidsraad, 2001

* Gezondheidsraad. Bevolkingsonderzoek naar darmkanker. Den Haag: Gezondheidsraad, 2009

* Heresbach D, Manfredi S, D'Halluin PN, Bretagne JF, Branger B. Review in depth and meta-analysis of controlled trials on colorectal cancer screening by faecal occult blood test. Eur J Gastroenterol Hepatol 2006; 18: 427-433.

* Hol L, Wilschut JA, Ballegooijen M van, et al. Screening for colorectal cancer: random comparison of guaiac and immunochemical faecal occult blood testing at different cut-off levels. Br J Cancer 2009; 100: 1103-1110

* Hol L, Leerdam ME van, Ballegooijen M van, et al. Screening for colorectal cancer: randomised trial comparing guaiac-based and immunochemical faecal occult blood testing and flexible sigmoidoscopy. Gut 2010; 59 : 62-68.
* Hüppe D, Hartmann H, Felten G, et al. Die Vorsorgekoloskopie rettet Leben - Ergebnisse der Herner Vorsorgedatei. Z Gastroenterol 2008; 46: $193-200$

* Lansdorp-Vogelaar I, Ballegooijen M van, Zauber AG, Habbema JD, Kuipers EJ. Effect of rising chemotherapy costs on the cost savings of colorectal cancer screening. J Natl Cancer Inst 2009; 101: 1412-1422.

* Morikawa T, Kato J, Yamaji Y, Wada R, Mitsushima T, Shiratori Y. A comparison of the immunochemical fecal occult blood test and total colonoscopy in the asymptomatic population. Gastroenterology 2005; 129: 422-428.

* Mulder SA, Ouwendijk RJ, Giard RW, Leerdam ME van, Kuipers EJ. Risk analyses for screening sigmoidoscopy based on a colorectal cancer (CRC) population. Scand J Gastroenterol 2009; 44: 205-210.

* Niv Y, Hazazi R, Levi Z, Fraser G. Screening colonoscopy for colorectal cancer in asymptomatic people: a meta-analysis. Dig Dis Sci 2008; 53 : 3049-3054.

* Regula J, Rupinski M, Kraszewska E, et al. Colonoscopy in colorectalcancer screening for detection of advanced neoplasia. N Engl J Med 2006; 355: 1863-1872.

* Rossum LG van, Rijn AF van, Laheij RJ. Random comparison of guaiac and immunochemical fecal occult blood tests for colorectal cancer in a screening population. Gastroenterology 2008; 135: 82-90.

* Rossum LG van, Rijn AF van, Munster IP van, et al. Earlier stages of colorectal cancer detected with immunochemical faecal occult blood tests. Neth J Med 2009; 67: 182-186.

* Segnan N, Senore C, Andreoni B, et al. Comparing attendance and detection rate of colonoscopy with sigmoidoscopy and FIT for colorectal cancer screening. Gastroenterology 2007; 132: 2304-2312.

Summary

Nationwide colorectal cancer screening

Usually, colorectal cancer presents with complaints in a late stage, but can be detected in an earlier stage, with better prognosis, by colonoscopy. Using colonoscopy, also precancerous tumours, adenomas, can be detected and excised, but only in a national screening programme. However primary screening with colonoscopy is too burdensome and expensive. Out of all the screening alternatives, only of the faecal occult blood tests (faeces tests) a decreased colorectal cancer mortality has been proven. It stands to reason that the new generation immunochemical faeces tests, can reduce colorectal cancer mortality more effectively, and these tests have, more than the alternatives, a good balance between efficiency, straightforwardness and costs. Recently, the Dutch National Health Council recommended to introduce nationwide colorectal cancer screening, using an immunochemical faecal occult blood test

\section{Bron}

L.G.M. van Rossum ${ }^{1}$, R.J.F. Laheij ${ }^{2}$, J.B.M.J. Jansen ${ }^{3}$

Uit 'de afdeling Epidemiologie, Biostatistiek en Health Technology Assessment van het Universitair Medisch Centrum St Radboud en ${ }^{2}$ de afdeling Maag-, Darm- en Leverziekten van het Universitair Medisch Centrum Utrecht en ${ }^{3}$ de afdeling Maag-, Darm- en Leverziekten van het Universitair Medisch Centrum St Radboud

Datum van acceptatie: 4 maart 2010

Adres: dr. L.G.M. van Rossum, UMC St Radboud, EBH 133, Postbus 9101 , 6500 HB Nijmegen

I.vanrossum@ebh.umcn.nl 